\title{
Index
}

acceleration, 7, 20

Accepted Programme, 59, 65, 94, 98, 103, 106, 137, 144, 149

accounts (Contractor's), inspection see inspection activity schedule, 33, 36, 38, 41-43, 44, 45, 46, 49-51, 61, $67,125,149$

conducting tender evaluation, 27

in Contract Data, 85, 92, 97, 104, 107, 119

priced contract with, 40, 41-43

target contract with, 49-51

works designed (by contractor)

fixed price, 17

target cost, 19

additional Client liabilities, 101, 110

additional compensation events, 100, 110

additional conditions of contract, 41, 54, 66, 87, 95, 116

additional insurances, 101-102, 111

Adjudicator, 56, 57, 86, 87, 88, 112

administration and management of contract, 2, 7, 13, 50

advanced payment (to Contractor), 61, 114, 129

bond, 61, 129, 150

agreement

articles of, 33

long-term, 10-13

on procurement strategy, 5

amendments to Inspections Plan, 68

arbitration, 13, 57, 86, 111

assessment date, 99, 108, 149

activities designed to suit, 43

activities spanning, 42

cost-based contracts, 56

priced contract with activity schedule, 41-42

target contracts, 50

award

the contract, 6-7, 31

Inspection Plan and, 50

letters of, 9-10

the recommendation, 6

see also post-award; pre-award

bill of quantities, 16, 17, 33, 36, 43-44, 61, 125, 149

in Contract Data, 85, 92, 97, 104, 110, 119

priced contract, $40,43-44$

target price contract, 44, 46, 51

bonds, 129, 150

advanced payment, 61, 129, 150

performance, 58, 61, 89, 92, 114, 129, 150 retention, 115,150

ultimate holding company guarantee, $23,33,59,61,89$, $90,113,129,149$

bonus for early completion, 59, 90, 113

boundaries

of Site, 106, 144-145

of Working Areas, 144-145

brief (requirement)

Client's see Clients

design, 135

developing, 5

budget, establishing the, 5

business

focus on programme and, 10-11

procurement as critical to success of, 11

capital outlay, 92

charges, 116

Inspection Plan, 77-78

clarity, 1, 125, 139, 140

Client's objectives, 40

tenders, 6

Clients

additional liabilities, 101, 110

clarity with objectives, 40

Contract Data (CD) provided by

part 1 of chapter, 85

part 2 of chapter, $85-86$

part 3 of chapter, $88-94$

part 4 of chapter, 97-102

part 5 of chapter (= CD part one by Client), $105-116$

Contract Data choices by, 95-96, 102

effective partnership and contribution from, 13

financial control exercised by, 52-54

requirements, 14

works to start immediately without, 20

Senior Representatives of both Contractors and, 56, 57, $86,87,88,112,119$

services and facilities to be provided by, for use by Contractor, 131

services and facilities to be provided by Contractor for use by, 130-131

tenders from see tenders

termination by, 60, 84, 91, 102, 104, 106, 114, 115

undertakings to, 60, 91, 113, 149

wanting to see programme, 98, 103, 118

works designed by, 127, 135 
collaboration, multiparty, 60-61, 92, 114

see also co-operation; partnership

commercial part of tender, evaluation, 22, 23, 24, 25-26

communication system, 147

compensation events, 13, 100, 109-110, 137

in Contract Data, 100, 104, 106, 109-110

additional, 100, 110

cost-reimbursable contracts, 51

priced contracts, $42-43,44$

target contracts, 50

completion, 128, 147

early see early completion

late, 90

in Scope, 128

sectional, 20, 59, 90, 113

Completion Date, 59, 90, 99, 107, 128, 147

completion date, 97, 98, 103, 107, 117, 118

conditions of contract, 9, 14, 15, 32, 52, 54, 58, 67, 70, 73, $85,87,95,101,105$

additional, 41, 54, 66, 87, 95, 116

in Scope, 124, 127, 141, 143, 147

confidentiality, 30, 66

consistency, examination of, 80

continuous improvement, 11

contract(s)

aspects, 32

award the, 6, 31

conditions of see conditions of contract

documents, 32-33

Scope and, 125-126

form of, 33

formation, 32

management and administration, 2, 7, 13, 50

multiparty see multiparty contracts

Options see Options

prices see prices

strategies, 8, 36, 84, 91, 96

finalising, 6

structure, 38

from tendering to, 14-16

termination by Client, 60, 84, 91, 102, 104, 106, 114, 115

traditional, 6, 36, 58, 62, 92, 128, 130

Contract Data (CD), 33, 83-122

boundaries of site and Working Areas, 145

structure of chapter

part 1 (CD1), 84, 85

part 2 (CD2), 84, 86-88

part 3 (CD3), 84, 89-93

part 4 (CD4), 84, 96-104

part 5 (=CD part one by Client), 84, 105-116

part 6 (=CD part two by Contractor), $84,117-122$

in tender evaluation, 26

example, 25

Contract Date, 62, 98, 103, 108, 114, 149, 150

Contractors

accounts and records plan, inspection, 67-81

Clients, Senior Representatives of both Clients and, 56, $57,86,87,88,112,119$
Contract Data (CD) by

part 2 of chapter, 88

part 3 of chapter, 95-96

part 4 of chapter, 102

part 5 of chapter (= CD part two by Contractor),

$$
117-120
$$

design see design

early Contractor involvement, 19, 36, 37, 65, 94, 96, 116, 120

list of items to consider in submitting a tender, 27

management contractor, 36, 51

payment see payments

responsibilities see responsibilities

services and facilities to be provided by

for use by Client and Others, 130

for use by Contractor, 131

share, 44, 45-49, 50, 109

structure of tender from, 16

visits to site, 140, 143

works designed by, 17-19, 124, 125, 147

Contracts (Rights of Third Parties) Act (1999), 66, 95, 116

co-operation/working with Others, 132, 148

see also collaboration; partnership

correcting Defects, 62, 92-93, 108, 149

$\operatorname{cost}(\mathrm{s}), 55$

cost reimbursable contracts, 17, 36, 39, 45, 52, 58, 59, 67

Defined Cost see Defined Cost

Disallowed Cost, 44-45, 49, 56, 70, 71, 74, 77, 80, 149

inflation and see inflation

labour, 73, 80, 81

overall

accuracy, 53

spot checks, 77

target cost see target contracts

trade-offs between time and quality and, 30-40

whole-life cost, 4, 5, 64-65, 115

see also Charges; exchange rates; price; Schedule of Cost

Components; Short Schedule of Cost Components

critical business activity, procurement as, 11

currency, 59, 100, 108, 109

multiple, 36, 58-59, 89, 112

damages

delay, 59-60, 90, 113

low-performance, 63, 93, 115, 135

dates

assessment see assessment date

Completion Date, 59, 90, 99, 107, 128, 147

completion date, 97, 98, 103, 107, 117, 118

Contract Date, 62, 98, 103, 108, 114, 149, 150

defects dates, 59, 64, 108, 148

Key Dates, 7, 64, 66, 97, 107

starting date, 53, 56, 57, 74, 107

see also time issues and timescales

defect correction period, 62, 108

Defects, 124-125, 147, 148, 149

correcting, 62, 92-93, 108, 149

liability for, 61, 63, 92, 115

meaning, 124-125, 147

notified, 108, 128, 147 
in Scope, 124, 125, 128, 137

searching for, 148

defects dates, 59, 64, 108, 148

Defined Cost, 19, 36, 52, 54-56, 58, 59, 65

assessing and verifying, 54-56

in completing Contract Data, 85, 94, 97, 100, 107, 116, $117,121,122$

cost reimbursable contract, 51, 53, 54, 54-56

in inspection of Contractor's accounts and records plan, $67,68,72,77,78,79,80$

target contract, 44, 45, 46, 47, 49, 50

delay damages, 59-60, 90, 113

demolition materials, title to, 132-133

design, 61-62, 79-81, 135-136

Contractor's, 61-62

in Contract Data, 91, 92, 102, 114-115, 117, 119

in Scope, 124, 125, 126, 135, 136, 147, 148, 150

in example tender evaluation, 25

in Manufacture and Fabrication, 79-81

in Short Schedule of Cost Components, 26

see also works designed

design-and-build approach, 5, 10, 16, 18, 19, 20, 126, 135

design personnel, 80

Disallowed Cost, 44-45, 49, 56, 70, 71, 74, 77, 80, 149

Dispute Avoidance Board, 36, 56, 57, 87, 88, 112, 120

dispute resolution and avoidance, $13,56-57,86-88$, $111-112,119-120$

Option W1, 56-57, 84, 86, 87, 88, 105, 111, 112, 140-141

Option W2, 56, 57, 66, 84, 86, 87, 88, 105, 111, 112, 119,141

Option W3, 56, 57, 84, 86, 87, 105, 111, 112, 120

Dispute Resolution Service Contract, NEC, 56, 57

drafting the Scope, general rules in, 139-142

see also redrafting

drawings, 125, 136-137

for information purposes only, 143-144

duties see responsibilities

early completion, 90

bonus for, 59, 90, 113

early Contractor involvement, 19, 36, 37, 65, 94, 96, 116, 120

early warnings, 106, 139

Early Warning Register, 106, 117

economic cycle, 12

recession, 11, 12

Engineering and Construction Contract (general and background aspects), 1-2

see also contract

Equipment

design, 136

Inspection Plan, 73-75, 78, 79

Schedule of Cost Components, 25, 73

EU law and regulations, 7, 9, 20, 22, 30

excavation materials, title to, 132-133

exchange rates, 58, 89, 100, 112

Fabrication see Manufacture and Fabrication facilities and services in Scope, 130-131 feasibility study, 16, 20

fee percentage, 25, 26, 27, 45, 56, 117, 122

in example tender evaluation, 25

filing (Inspection Plan)

Charges, 78

design, 81

Equipment, 75

Manufacture and Fabrication, 79

People, 73

Plant and Materials, 76, 78

Subcontractor, 72

financial control exercised by Client, 52-54

financial risk see risk

fitness for purpose, 61-62, 92

fixed price, $17,18,19,20,38,39$

guaranteed maximum price, 45

head page (tender document), 30

health and safety, 5, 136

Housing Grants, Construction and Regeneration Act 1996 (HCGR), 36, 56, 57, 65-66, 86, 87, 94, 95, 112

inflation

adjustment for, 58, 112

taking risk of, 89

information

model/modelling, 60, 91, 114, 120, 150

for Project Team to provide see Project Team

in Scope, 114, 120

to consider in drafting, 139

drawings for information purposes only, 143-144

Site see Site

in tendering

for invitation to tender to include, 22

submitted with tender, 23

Information Execution Plan, 60, 91, 95, 114, 120

inspections, 54-55, 67-81, 134-135

Contractor's accounts and records plan, 54, 67-81

amendments, 68

basis, 67

Charges, 77-78

Comment Sheet, 68

design, 79-81

distribution, 68

Equipment, 73-75, 78, 79

goals, 68

main objectives, 67-68

People, 72-73

Plant and Materials, 75-77, 78, 79

Subcontractors, 70-72

reporting see reporting

Scope requirements, 134-135

insurances, 101-102, 104, 110-111

additional, 101-102, 111

intent, letters of, 10

interest payments, 109, 116

interface management (multiparty contractors), 137-139

Site Information and, 143 
introduction (tender document), 30

invitation to tender see tenders

Key Dates, 7, 64, 66, 97, 107

Key Performance Indicators, 52, 60, 64, 92, 93, 115

key persons, 23, 24, 27, 65, 96, 117, 120

\section{labelling, 136-137}

labour costs, 73, 80, 81

language, 31, 106

in drafting the Scope, 140

late completion, 90

law and regulations, 106

changes in, 58, 89, 112

risk of, 58,89

EU, 7, 9, 20, 22, 30

letters

of award, 9-10

of intent, 10

of invitation, 30

liability, 93, 101, 110

additional Client liabilities, 101, 110

in Contract Data, 92, 93, 104, 115

for Defects, 61, 63, 92, 115

limitation of, $60,63-64,93,115$

limitation of liability, 60, 63-64, 93, 115

long-term agreement, 10-13

low-performance damages, 63, 93, 115, 135

Main Options, 36, 36-40, 127

in Contract Data, 85, 89, 97, 100, 104, 105, 107, 117, 119,121

management and administration of contract, 2, 7, 13, 50 management contractor, 36, 51

Manufacture and Fabrication, 78-79

in example tender evaluation, 25

in Inspection Plan, 78-79

materials

from excavation and demolition, title to, 132-133

off Site, 133

standards of, 141

see also Plant and Materials

maximum price, guaranteed, 45

Monthly Inspection Report, 67

Charges, 78

design, 80, 81

Manufacture and Fabrication, 79

People, 72, 73

Plant and Materials, 76

Subcontractor, 72

multiparty contracts

collaboration, 60-61, 92, 114

see also cooperation

interface management see interface management multiple currencies, 36, 58-59, 89, 112

multiplicity of use, 13

NEC see New Engineering Contracts

need, defining the, 5 negotiation, post-tender, 31

New Engineering Contracts (NECs - family), 2, 56, 124,

$125,139,140$

Dispute Resolution Service Contract, 56, 57

NEC4, 2, 13, 18, 20, 37, 57, 85, 105

non-subcontracted works, 55

notified Defects, 108, 128, 147

off Site materials, 133

Official Journal of the European Union (OJEU) notice for public sector and utilities procurement, 17, 18

one-stage procurement process, 17, 18

Option(s), 35-66

Main see Main Options

secondary see secondary Options

optional statements in Contract Data, 84, 86, 96-104, 105, $107,109,110,111,112,113,114,115,116,118,119$, 120,126

choosing, 96-104

Others

services and facilities to be provided for use by, 130-131 undertakings to, 60, 90, 113, 149

working/cooperating with, 132, 148

overall costs see costs

partnership, effective, 13

see also collaboration

payments, 57,59

advanced 61 see advanced payment

in Contract Data, 85, 89, 99-100, 104, 108-109, 119

final date for, 116

in Inspection Plan, 70, 77

build-up to, 77, 78

individual payslip examination, 72, 79

Plants and Materials and Equipment, 73, 74, 78

random examination, 77

interest, 109, 116

period for, 94, 99, 116

increases in, 99

priced contract

with activity schedule, 41-42

with bill of quantities, 44

procedures, 56, 65, 66

to Subcontractor, 70

target contract

with activity schedule, 49-50, 50

of Contractor's share, 46-47

people/persons/personnel

design personnel, 80

Inspection Plan, 72-73

key persons, 23, 24, 27, 65, 96, 117, 120

labour costs, 73, 80, 81

payslips (of individuals), examination, 72, 79

people rates in Short Schedule of Cost Components, 26 performance

bond, 58, 61, 89, 92, 114, 129, 150

Key Performance Indicators, 52, 60, 64, 92, 93, 115

low, damages for, 63, 93, 115, 135

period for reply, 106 
period for retention, 114, 150

persons and personnel see people

Plant and Materials, 101, 104, 111, 130

Contract Data, 101, 111, 121

Inspection Plan, 75-77, 78, 79

see also materials

post-award tasks (Inspection Plan), 70

post-orders

Equipment, 73-75

Plant and Materials, 75

post-tender negotiation, 31

pre-award tasks (Inspection Plan), 70

pre-orders

Equipment, 73

Plant and Materials, 75

previous specifications, 9

price (and pricing), 33

fixed price contracts, 17, 18, 19, 20, 38, 39

inflation and see inflation

priced contracts, 36, 39, 40-44

target see target contracts

see also cost

Price for Work Done to Date, 52, 61, 63, 67

final, 44, 47-49

priced contracts, 42

target contracts, 44, 45, 47, 48, 49

procurement, 3-20

effective, generic good principles for, 9

procedures, 129

process, 5-7

steps in cycle, 17, 18, 20

public sector see public sector procurement

routes, $8,16,17,18$

scenarios, 15-20

strategy, $7-8$

agreeing on, 5

what it is, 8

what it is, 4

productivity-based examination of individual payslips, 79

Professional Service Contract, 18, 19, 20, 37, 52

programmes

acceptance

Accepted Programme, 59, 65, 94, 98, 103, 106, 137, 144, 149

submission for, 148

activities too small to include in, 42

Client wanting to see, $98,103,118$

conducting the tender evaluation, 26

management of, 127-128

no programme identified in part two of Contract Data, 107

Project Bank Account, 65, 94, 96, 116, 120

project-by-project focus, 10

Project Manager

conducting tender evaluations, 27

effective partnership and, 13

interface management and, 138

Project Team, 138

establishing, 5 information to be provided by (Inspection Plan)

Charges, 78

design, 81

Equipment, 75

people, 73

Plant and Materials, 77

protection and security, 130

public sector procurement, 9

$O J E U$ notice for public sector and utilities procurement, 17,18

quality

management, 99, 104, 118, 119, 130, 148

of Scope, 39

trade-offs between cost and time and, 30-40

of works, 134

recession, economic, 11,12

reclaimed materials, 133

records (Contractor's), inspection see inspection

redrafting, 14

regulations see law and regulations

reinforcement schedules, 136

reporting and reports (Inspection Plan), 68

Charges, 77, 78

Design, 80, 81

Equipment, 73

Manufacture and Fabrication, 79

People, 72

Plant and Materials, 76

Subcontractors, 72

requirement see brief

responsibilities (duties and roles) of Contractor

main, 97, 102, 107, 118

other, 132

retention, 58, 62-63, 115

bond, 115,150

period for retention, 114, 150

target contract with activity schedule, 50

rights, 149

transfer of, 60, 91, 114

see also Contracts (Rights of Third Parties) Act

risk (financial), 49, 54

apportioning, 46

balance of (for each main Option), 38

extent, 45

of inflation, 89

of law changes, 58,89

managing, 24, 40, 51

priced contract

with activity schedule, 41

with bill of quantities, 43

roles see responsibilities

safety (health and), 5, 136

salvaged materials, 133

Schedule of Cost Components, 18, 22, 26, 49, 54, 55, 56, 121

charges, 77 
Schedule of Cost Components (continued)

data for, 117, 121

design, 79

Equipment, 25, 73

in example tender evaluation, 25

Manufacture and Fabrication, 78

people, 72

Plant and Materials, 74

Scope, 33, 123-150

clauses, 126, 147-150

in Contract Data, 85, 105

changes to, 85,94

contract documents and, 125-126

cost forecasts and, 53

drafting, general rules in, 139-142

general aspects, 126-127

guidelines, 123-150

quality and standard, 39

separation of Site Information and, 125

structuring, 126-137

what to include, 124-125

where it fits into contract documents, 125-126

secondary Options, 19, 36, 37, 58-66

in Contract Data, 84, 89-96, 105, 112, 120

sectional completion, 20, 59, 90, 113

security and protection, 130

Senior Representatives (of Clients and Contractors), 56, 57, $86,87,88,112,119$

services and facilities in Scope, 130-131

share (Contractors), 44, 45-49, 50, 109

Short Schedule of Cost Components, 18, 22, 26

compensation events, 43, 44

data for, 121, 122

example tender evaluation, 26

simplicity, 1, 2, 125

Site, $142-145$

boundaries, 106, 144-145

definition, 144

Site Information, 2, 33, 106, 124, 126, 142-145, 149

interface Contractors and impact of, 143

separation of Scope and, 125

using, 142-143

specific requirements for use of, 134

visits

by Contractor, 140, 143

in dispute resolution, 87, 112

of Manufacture and Fabrication, 78, 79

specifications

previous, 9

in Scope, 133-134, 139

spending on project-by-project basis, 10

spot checks, 71, 72

Charges, 77

Equipment, 74

labour costs, 80

Plant and Materials, 76

standard(s)

of materials, 141

of Scope, 39 starting date, 53, 56, 57, 74, 107

strategies see contracts; procurement

Subcontractors and subcontracts, 54, 129-130

Inspection Plan, 70-72

tender submission and, 27

undertakings to Others and Clients, 60, 90-91, 113, 149

Supervisors, 105, 148, 149

tests and inspections, 134

supply base, manageable, 10-11

take over of works, 99, 107, 128

parts/sections of works, 59, 60, 90, 128

target contracts, 17, 19-20, 36, 39, 44-51, 52, 67, 85

works designed by Contractor, 19-20

team see Project Team

technical part of tender, 26-27

evaluation, 22, 23, 24

tenders, 21-33

clarification, 6

conditions of tendering, 30-32

Contract Data entries completed by tender stage, 117

Contractors' tender structure, 16

cost forecasts and requests to tenderers, 53

documentation, 29-33

for effective procurement, 9

Parts A-C, 15

preparing, 6

evaluation/assessment, 6, 22-27, 31

conduct/process, 27, 31

criteria, 24-27

examples, 24-26

invitation to tender from Client (preparing the documentation), 17, 18, 31

information to include, 22, 30

issuing, 6, 17, 18

letter of, 30

structure, 15

negotiation after tendering, 31

priced contract

with activity schedule, 41

with bill of quantities, 43

procedure for tendering, 13-14

programme with see programme

receiving, 6

structure, 15

value for money and tenderers proposals, 5

termination by Client, 60, 84, 91, 102, 104, 106, 114, 115

tests, 133-134

time issues and timescales

Contract Data, 98-99, 103, 106, 107, 108, 118, 121

economic cycle, 12

Inspection Plans

Charges, 78

design, 79, 81

Equipment, 75

Manufacture and Fabrication, 79

People, 73

Plant and Materials, 77

Subcontractor, 72 
procurement, 7

trade-offs between time and cost and quality, 30-40

works, 134

see also dates

Title (Contract Data), 101, 104, 110

title to materials from excavation and demolition, 132-133

trade-offs in choosing a main Option, 30-40

traditional contracts, 6, 36, 58, 62, 92, 128, 130

transfer of rights, 60, 91, 114

trend tables (in Inspection Plan)

Charges, 77, 78

design, 80, 81

People, 73

tribunal, 56, 57, 86, 111

trust, 13

two-stage process

payment of Contractor's share, 46-47

procurement, 17, 18

ultimate holding company guarantee, 23, 33, 59, 61, 89,

$90,113,129,149$

undertakings, 90-91

to Clients, 60, 90, 113, 149

to Others, $60,91,113,149$

value

management, 52

for money, 4-5, 5, 11, 65, 70 vision vs view with long-term objectives, 12

visits to Site see Site

weather, 100, 109-110

weighting in tender evaluations, 6, 31

examples, 24

whole-life cost, 4, 5, 64-65, 115

work

provided, 131-132

specification see specifications

Working Areas, 121, 122, 133, 144-145

boundaries, 144-145

working areas, 106, 117, 145

working with Others (co-operation), 132, 148

see also partnership

workload security, 11

works

description of, 105, 124, 127

management, 127

non-subcontracted, 55

providing the, 54, 124, 145, 147

quality, 134

specific requirements/methods/sequence/timing of, 134

to start immediately without Clients requirements, 20

take over see take over

works designed, 17, 124

by Client, 127, 135

by Contractor, 17-19, 124, 125, 147 